\title{
PERANCANGAN SISTEM APLIKASI DESKTOP PENGELOLAAN DATA PEGAWAI PADA KLINIK SURYA MEDIKA
}

\author{
Fery Susanto \\ Teknik Informatika, Fakultas Teknik dan Ilmu Komputer, Universitas Indraprasta PGRI Jakarta \\ Jalan Raya Tengah No 80, Kelurahan Gedong, Pasar Rebo, Jakarta Timur \\ ferysusanto913@gmail.com
}

\begin{abstract}
ABSTRAK
Tujuan dari penelitian adalah untuk menganalisis penggunaan Perancangan Sistem Aplikasi Pengelolaan Data Pegawai pada Klinik Surya Medika. Metodologi penelitian yang digunakan untuk merancang Pengelolaan Sistem Informasi Kepegawaian adalah metodologi kualitatif. Selain itu penulis juga menggunakan metodologi wawancara, dan kepustakaan untuk mendapatkan data lebih lengkap. Metodologi Pengembangan sistem yang di gunakan menggunakan metodologi prototyping, yaitu pengembangan perangkat lunak yang menggunakan pendekatan untuk membuat rancangan dengan cepat dan bertahap sehingga dapat segera dievaluasi oleh calon pengguna. Manfaat metodologi prototyping ialah analisa kebutuhan lebih mudah diwujudkan serta mempersingkat waktu pengembangan produk perangkat lunak. Dapat disimpulkan, sistem aplikasi pengelolaan data pegawai dapat mempermudah dalam proses pencarian data pegawai dan mencegah terjadinya kehilangan data. Serta sistem kepegawaian ini diharapkan dapat memudahkan bagian kepegawaian dalam memasukan data yang menyangkut proses pengelolaan data pegawai.
\end{abstract}

Kata Kunci: Sistem, Aplikasi, Pengelolaan, Pegawai

\begin{abstract}
The purpose of the study was to analyze the use of the Employee Data Management Application System Design at Surya Medika Clinic. The research methodology used to design the Management of Personnel Information System is a qualitative methodology. In addition, the author also uses the interview methodology, and literature to obtain more complete data. Methodology The system development used uses a prototyping methodology, namely software development that uses an approach to make designs quickly and gradually so that they can be immediately evaluated by potential users. The benefit of the prototyping methodology is that requirements analysis is easier to implement and shortens software product development time. It can be concluded, the employee data management application system can simplify the process of searching for employee data and prevent data loss. And this staffing system is expected to facilitate the personnel department in entering data concerning the process of managing employee data.
\end{abstract}

Key Word: System, Application, Management, Employee.

\section{PENDAHULUAN}

Seiring dengan perkembangan zaman, perkembangan ilmu pengetahuan dan teknologi (IPTEK) saat ini sudah cukup maju, khususnya teknologi informasi yang telah mengalami perkembangan begitu pesat. Hal tersebut ditandai dengan semakin meningkatnya pengguna komputer dalam menangani pengolahan data. Untuk sekarang ini penggunaan komputer menjadi salah satu pilihan utama disetiap instansi, baik yang berskala besar maupun kecil.

Klinik Surya Medika merupakan sebuah klinik penyedia layanan kesehatan masyarakat yang berada di daerah Ciracas , Jakarta Timur.

Proses pengolahan data kepegawaian di lingkungan Klinik Surya Medika sudah menggunakan komputer yaitu dengan menggunakan Microsoft excel sehingga masih kurang efesian dalam proses pengolahan data, baik memasukan data, merubah data dan menghapus data yang tidak diperlukan lagi serta masih kurang cepat dalam proses pencarian data.

Dengan permasalahan tersebut, perlu adanya suatu sistem yang terkomputerisasi dalam penyelesaiannya.

Sistem merupakan suatu kumpulan dari komponen-komponen yang membentuk satu kesatuan (Agus Gunawan, 2019)

perancangan sistem adalah sekumpulan aktivitas yang menggambarkan secara rinci bagaimana sistem akan berjalan. Hal itu bertujuan untuk menghasilkan produk perangkat lunak yang sesuai dengan kebutuhan user (Villela, 2015). 
Berdasarkan dari kedua definisi di atas, maka penulis dapat simpulkan bahwa sistem adalah sekumpulan elemen-elemen yang saling berinteraksi untuk suatu tujuan tertentu.

Berdasarkan latar belakang masalah diatas maka rumusan masalah pada skripsi ini adalah bagaimana merancang sistem informasi pengelolaan data pegawaian yang bisa memberikan kemudahan kepada pihak Klinik Surya Medika meliputi efektivitas, dan efisiensi dalam pendataan pegawai.

\section{METODOLOGI PENELITIAN}

Metodologi penelitian adalah metodologi yang digunakan untuk mengetahui hasil dari penelitian dengan cara mengumpulkan, mencatat dan menganalisa informasi data yang ada. Penulis menggunakan metodologi penelitian kualitatif. (Achmadi, 2011)

Penelitian kualitatif adalah pengumpulan data pada suatu latar alamiah dengan maksud menafsirkan fenomena yang terjadi dimana peneliti adalah sebagai instrument kunci kesatuan (Astuti et al., 2015)

Berdasarkan dari kedua definisi di atas, maka penulis dapat simpulkan bahwa Penelitian kualitatif adalah suatu penelitian yang menggunakan cara analisis atau melakukan pendekatan investigasi karena biasanya peneliti mengumpulkan data dengan cara bertatap muka langsung dan berinteraksi langsung dengan orang-orang ditempat penelitian.

Informasi adalah pengolahan data yang diinterprestasikan maupun diklasifikasi yang dipakai dalam proses untu kmengambil keputusan. (Hutahaean, 2015).

"Sistem informasi merupakan sebuah sistem yang komplek". Salah satunya dalam proses pencatatan data barang masih menggunakan sehingga sering terjadi kesalahan dan kehilangan data barang. (Tiara Dewi, Muhammad Amir Masruhim, 2016).

\section{HASIL DAN PEMBAHASAN}

\section{Analisa Permasalahan}

Dari latar belakang yang telah dijelaskan tersebut diatas, penulis mengidentifikasikan masalah dalam penelitian ini sebagai berikut:
1. Sistem pengolah data masih menggunakan Microsoft Excel dalam proses pencatatan data pegawai sehingga kurang terorganisir dan tertata rapi.

2. Dibutuhkan sistem yang memudahkan pengurusan dalam mengelola pengolahan data pegawai.

3. Peroses pendataan maupun pencarian memakan waktu yang lama.

Aplikasi adalah alat terapan yang difungsikan secara khusus dan terpadu sesuai kemampuan yang dimilikinya. (Roni, 2016)

XAMPP merupakan suatu software yang bersifat open source yang merupakan pengembangan dari LAMP (Linux, Apache, MySQL, PHP dan Perl) (Tatang, 2019)

Java merupakan bahasa berorientasi objek untuk pengembangan aplikasi mandiri, aplikasi berbasis internet, aplikasi untuk perangkat cerdas yang dapat berkomunikasi lewat internet/ jaringan komunikasi. (Lilip, 2017)

MySQL adalah sebuah software open source yang digunakan untuk membuat sebuah database. (Fitria, 2013)

\section{Alternatif Penyelesaian Masalah}

Untuk mencari solusi dalam permasalahan yang ada maka penulis membuat suatu sistem yang akan membantu dalam menyelesaikan masalah tersebut. Berdasarkan analisa sistem yang sedang berjalan saat ini penulis melihat beberapa kelemahan dan pokok permasalahan yang terdapat pada sistem informasi laporan data pegawai Klinik Surya Medika, maka penulis memberikan saran beberapa alternatif penyelesaian masalah diantaranya:

1. Membangun sistem penjualan yang efektif, efisien dan user friendly.

2. Penulisan skripsi ini bertujuan untuk menghasilkan sebuah aplikasi sistem informasi kepegawain yang nantinya akan digunakan oleh pihak Klinik Surya Medika

3. Membuat aplikasi dekstop sistem informasi kepegawain menggunakan program java netbeans dan xampp.

4. Penerapan dan uji coba program sistem informasi kepegawain untuk membantu mengatasi masalah yang ada pada Klinik Surya Medika 


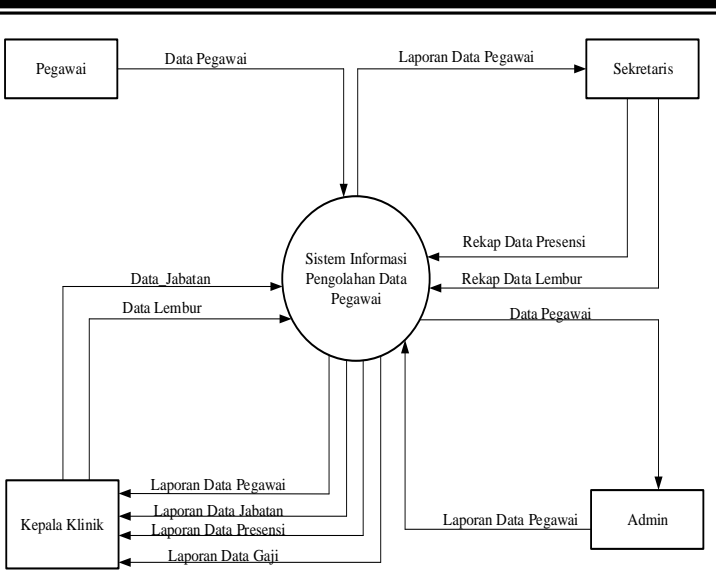

Gambar 1. Diagram Konteks

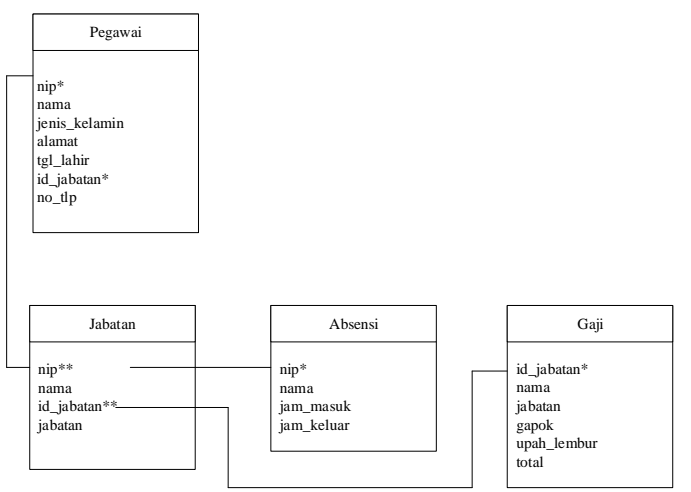

Gambar 2. Normalisasi

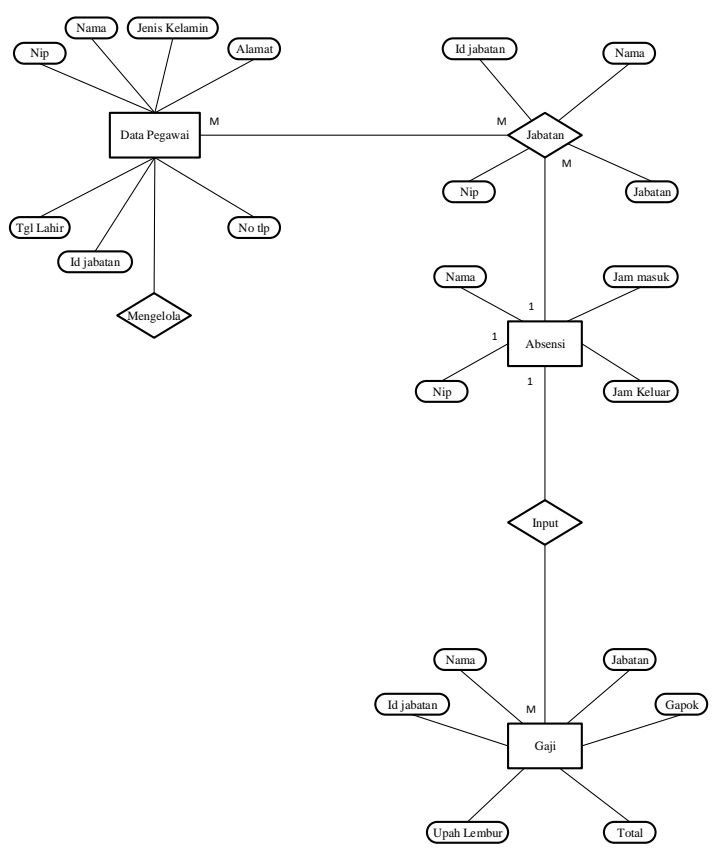

Gambar 3. ERD (Entity Relationship Diagram)

Berikut adalah tampilan layar dan hasil pengujian pada software program yang telah di buat dengan bahasa pemrograman Java.

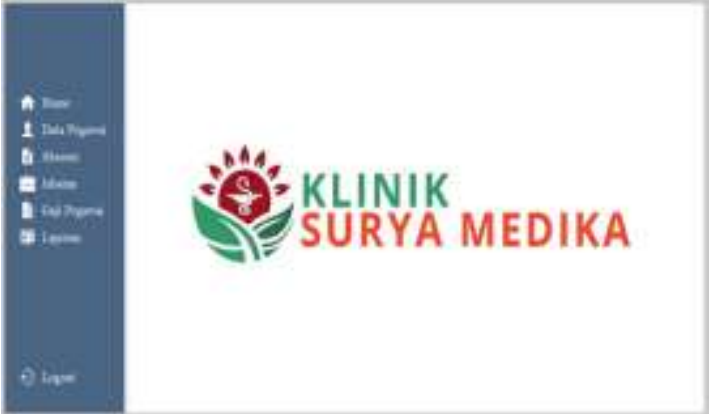

Gambar 4. Form Menu Utama

Tampilan layar di atas merupKn tampilan Menu Utama pada Sistem Informasi Kepegawaian Pada Klinik Surya Medika. Pada layar utama tersedia menu bar yang terdiri dari master data yang digunakan untuk memasukkan data yang berkaitan dengan data pegawai, data jabatan, data presensi,data gaji dan laporan-laporan.

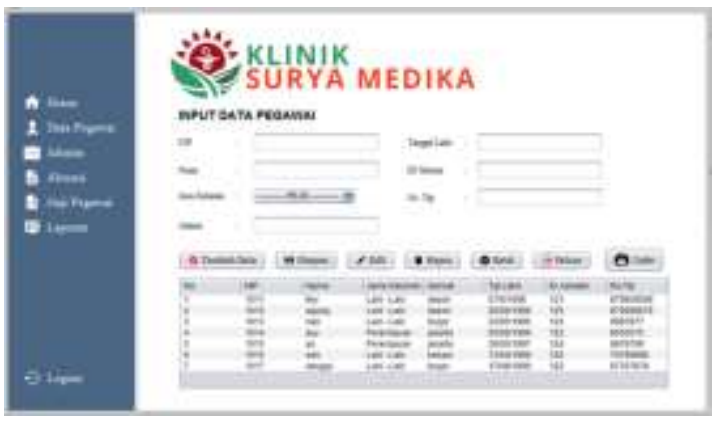

Gambar 5. Form Data Pegawai

Tampilan ini merupakan tampilan input data pegawai yang ada dalam sistem kepegawaian pada Klinik Surya Medika.

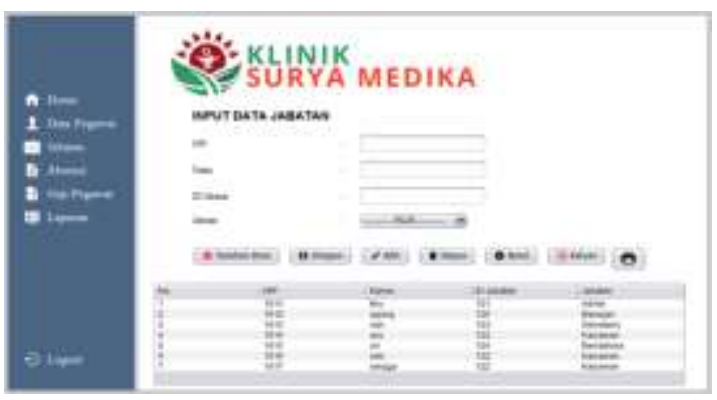

Gambar 6. Form Data Jabatan

Tampilan ini merupakan tampilan layar data jabatan pegawai yang ada dalam sistem kepegawain Klinik Surya Medika. 


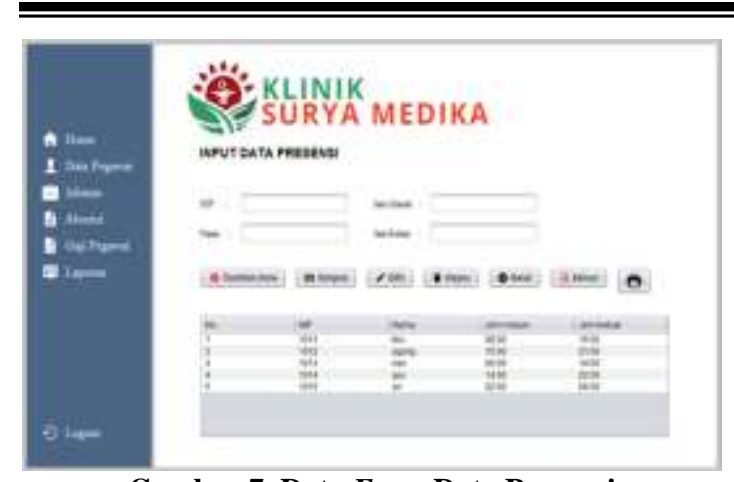

Gambar 7. Data Form Data Presensi

Tampilan layar diatas merupakan tampilan layar data presensi di dalam sistem kepegawain pada Klinik Surya Medika. Tampilan ini adalah dimana admin memasukan data presensi pegawai

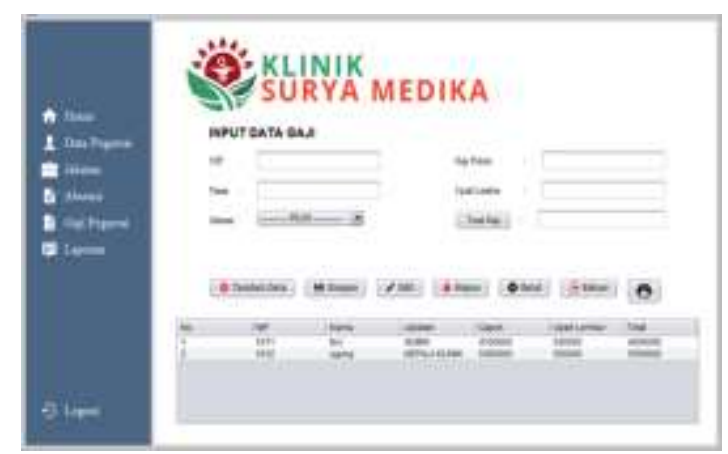

Gambar 8. From Data Gaji

Layar di atas menampilkan tampilan form laporan data penggajian pegawai.

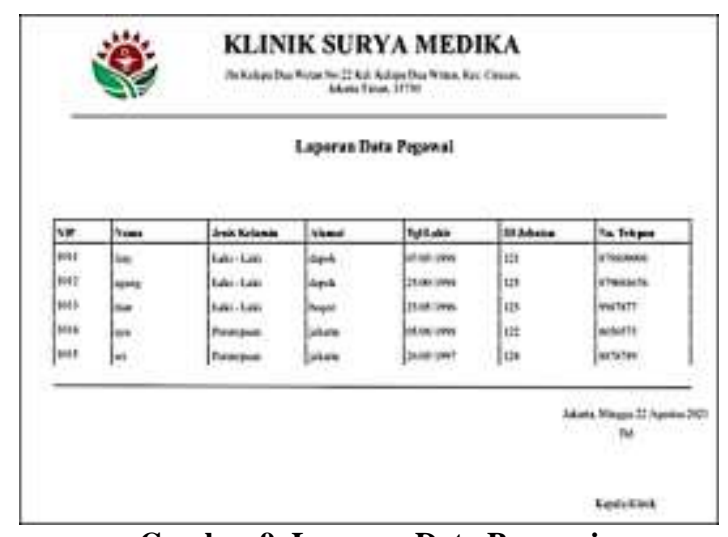

Gambar 9. Laporan Data Pegawai

Layar di atas menampilkan tampilan form laporan data pegawai. Pada layar form data pegawai digunakan untuk mengecek laporan data kepegawain.

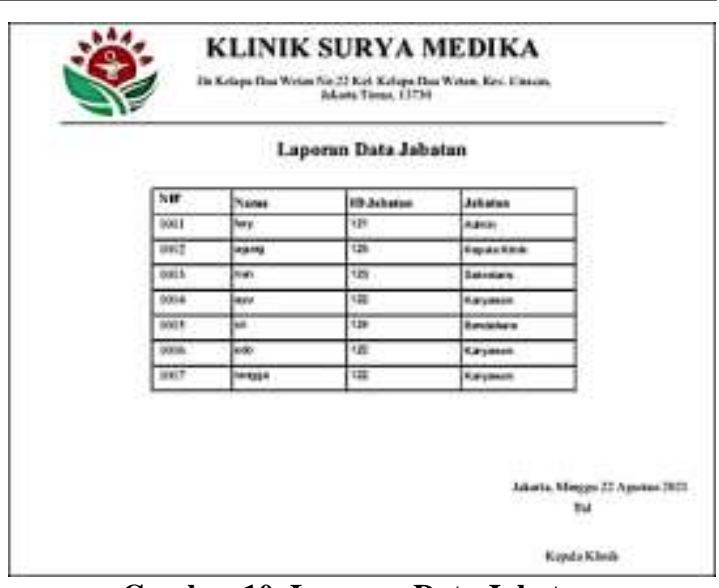

Gambar 10. Laporan Data Jabatan

Layar di atas menampilkan tampilan form laporan data jabatan pegawai.

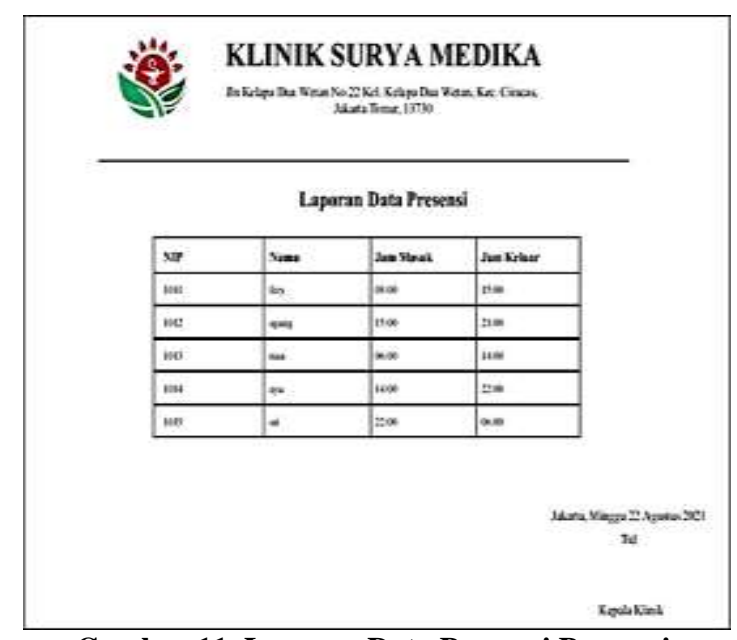

Gambar 11. Laporan Data Presensi Pegawai

Layar di atas menampilkan tampilan form laporan data presensi pegawai.

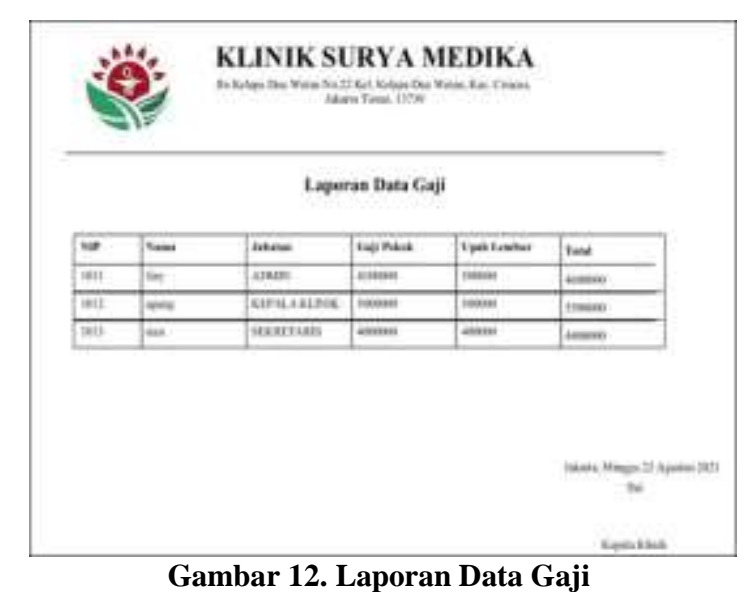

Gambar 12. Laporan Data Gaji

Layar di atas menampilkan tampilan form laporan data gaji pegawai. 


\section{SIMPULAN DAN SARAN}

Dari hasil penelitian dan pembahasan, maka penelitian ini dapat disimpulkan sebagai berikut: 1) Sistem ini diharapkan dapat mempermudah bagian kepegawaian dalam proses pencarian dan penginputan data yang menyangkut proses pengelolaan data pegawai. 2) Dengan memakai sistem yang terkomputerisasi, kesalahan dapat terdeteksi dan dapat segera diperbaiki. 3) Sistem ini dapat meningkatkan efektifitas dan efesiensi kerja karyawan di Klinik Surya Medika.

Sejalan dengan sistem yang penulis buat, penulis mengemukakan saran bahwa sistem aplikasi ini masih harus dikembangkan lagi, baik dari segi fitur maupun dari pemeliharaannya, agar dapat memenuhi kebutuhan dan tidak menghambat operasional kerja. Diantaranya adalah: 1) Aplikasi pendukung ini bisa dioptimalkan dengan melakukan pengembangan fitur-fitur yang dibutuhkan agar dapat mempermudah pengguna. 2) Aplikasi pendukung ini bisa dikembangkan lagi dari segi tampilan user interface-nya agar pengguna merasa lebih nyaman, mudah dan cepat dalam menggunakanya. 3) Proses backup data harus dilakukan dalam suatu periode tertentu agar terhindar dari hal-hal yang tidak diinginkan yang bersifat merugikan.

\section{DAFTAR PUSTAKA}

Achmadi, A. \& N. (2011). Teori Metodologi Penelitian. Teori Metodologi Penelitian, $1-21$.

Agus Gunawan. (2019). Bab Ii Landasan Teori. Journal of Chemical Information and Modeling, 53(9), 8-24.

Astuti, S. I., Arso, S. P., \& Wigati, P. A. (2015). 済無No Title No Title No Title. Analisis Standar Pelayanan Minimal Pada Instalasi Rawat Jalan Di RSUD Kota Semarang, 3, 103-111.

Fitria. (2013). Pengertian Menurut Para Ahli. Journal of Chemical Information and Modeling, 53(9), 1689-1699.

Hutahaean, J. (2015).. Konsep Dasar Sistem Informasi, 1-36.

Lilip. (2017). Tinjauan Pustaka Landasan Teori. 5-22.

Roni, A. A. C. (2016). Aplikasi Pemesanan Bahan Kimia Pertanian pada CV. Gilang Perkasa Berbasis Web. 6-20. http://eprints.polsri.ac.id/3929/

Tatang. (2019). Bab Ii Landasan Teori. Journal of Chemical Information and Modeling, 53(9), 1689-1699.

Tiara Dewi, Muhammad Amir Masruhim, R. S. (2016). 済無No Title No Title No Title. Laboratorium Penelitian Dan Pengembangan FARMAKA TROPIS Fakultas Farmasi Universitas Mualawarman, Samarinda, Kalimantan Timur, April, 5-24.

Villela, lucia maria aversa. (2015). John Buch. Journal of Chemical Information and Modeling, 53(9), 1689-1699. 